\title{
A Registry-Based Study on the Association Between Human Salmonellosis and Routinely Collected Parameters in Michigan, 1995-2001
}

\author{
M. MOKHTAR ARSHAD, ${ }^{1,2}$ MELINDA J. WILKINS, ${ }^{3}$ FRANCES P. DOWNES, ${ }^{4}$ \\ M. HOSSEIN RAHBAR, ${ }^{5}$ RONALD J. ERSKINE, ${ }^{1}$ \\ MATTHEW L. BOULTON, ${ }^{6}$ and A. MAHDI SAEED ${ }^{1,2,5}$
}

\begin{abstract}
Purpose: Salmonella serotypes are among the most common bacterial causes of foodborne gastroenteritis in the United States, associated with $\sim 1.4$ million human illnesses annually. Studies on trends of the serotypes and hostrelated factors are necessary for the development of effective prevention plans for foodborne diseases caused by these pathogens.

Materials and Methods: To determine the epidemiologic trends of human infections with the most common Salmonella serotypes in Michigan, we analyzed cases of culture-confirmed salmonellosis at the Michigan Department of Community Health (MDCH) from 1995 to 2001.

Results: A total of 6797 cases were reported, with an average annual incidence per 100,000 population (AAI) of 9.9. Among cases for which information on Salmonella serotype were available (6292 cases), the most common serotypes were $S$. Typhimurium (1596 cases, $26 \%$ ), followed by $S$. Enteritidis (1309, 22\%), S. Heidelberg (466, $8 \%$ ) and $S$. Newport (222, 4\%). From 1998 to 2001, the incidence of $S$. Typhimurium and $S$. Enteritidis decreased significantly by $39 \%$ (95\% confidence interval [CI], $49 \%$ to $26 \%$ decrease) and $32 \%$ (95\% CI, $44 \%$ to $18 \%$ decrease) respectively. Whereas the incidence of $S$. Newport increased by $101 \%$ (95\% CI, 25\% to $225 \%$ increase) and $S$. Heidelberg remained stable. Infection with these serotypes frequently occurred in the summer months. As a group, infants had the highest AAI for all Salmonella serotypes (75.0), S. Typhimurium (21.9), S. Enteritidis (14.0), S. Heidelberg (5.4), and $S$. Newport (1.7). Among patients whose race was known, blacks had a significantly higher AAI compared to whites for $S$. Typhimurium (2.5 vs. 1.3; $R R=2.3,95 \%$ CI, 1.6-3.3), S. Enteritidis (1.4 vs. 1.1; relative rate $(\mathrm{RR})=1.4 ; 95 \% \mathrm{CI}, 1.1-1.6)$, $S$. Heidelberg $(0.8$ vs. $0.3 ; \mathrm{RR}=3.6 ; 95 \% \mathrm{CI}, 2.8-4.6)$, and $S$. Newport $(0.3$ vs. 0.1 ; $\mathrm{RR}=2.8 ; 95 \% \mathrm{CI}, 1.9-4.2)$. Among patients whose ethnicity was known, Hispanics had a significantly higher AAI for $S$. Enteritidis compared to non-Hispanics (1.0 vs. 0.5; RR = 1.9; 95\% CI, 1.2-3.0), but not different significantly for $S$. Typhimurium, $S$. Heidelberg, and $S$. Newport.

Conclusion: This study revealed the emergence of $S$. Newportand the high incidence of the most common Salmonella serotypes among infants, people of African descent, and Hispanics. This information can be used by the state and local health departments of Michigan to enhance salmonellosis prevention efforts by rationalizing the allocation of appropriate public health resources and personnel.
\end{abstract}

\section{INTRODUCTION}

$S^{\wedge}$ ALMONELLA SEROTYPES ARE AMONG the most common bacterial causes of foodborne gastroenteritis. On a global scale, an estimated 1.3 billion cases of acute nontyphoidal gastroenteritis occur annually, resulting in 3 million deaths (WHO Report, 2000-2005). In the United States, Salmonella serotypes cause an estimated 1.4 million cases of foodborne illnesses annu-

Departments of ${ }^{1}$ Large Animal Clinical Sciences and ${ }^{5}$ Epidemiology; ${ }^{2}$ National Food Safety and Toxicology Center, Michigan State University, East Lansing, Michigan.

Bureaus of ${ }^{3}$ Epidemiology and ${ }^{4}$ Laboratories, Michigan Department of Community Health, Lansing, Michigan.

${ }^{6}$ School of Public Health, University of Michigan, Ann Arbor, Michigan. 
ally, resulting in over 100,000 physician office visits (Voetsch et al., 2004), 16,000 hospitalizations, and nearly 600 deaths (Mead et al., 1999).

Human infection with nontyphoidal Salmonella usually results in an acute self-limiting diarrhea that does not warrant antimicrobial therapy. However, these infections can also develop into life-threatening systemic infections including meningitis and endocarditis that require effective chemotherapy (Pegues et al., 2005). The estimated cost associated with salmonellosis in humans in the United States, including the costs of medical care and lost productivity, ranged from $\$ 0.5$ to $\$ 2.3$ billion annually (Frenzen et al., 1999).

Human nontyphoidal Salmonella infections often result from the consumption of contaminated foods of animal origin such as chicken, eggs, beef, pork, turkey, milk, or cheese (Gomez et al., 1997; Olsen et al., 2000; Sanchez et al., 2002). Other food vehicles identified include fish, shellfish, fresh fruits and juice, spices, chocolate, and vegetables/produce (Gomez et al., 1997; Olsen et al., 2000; Sivapalasingam et al., 2004).

Analyses of salmonellosis surveillance data allow estimation of the overall incidence and trends, and identification of groups at risk. The objectives of this study were to determine the trends in the incidence of human infections with the most common Salmonella serotypes in Michigan from 1995 to 2001 and to identify the population subgroups at high risk.

\section{MATERIALS AND METHODS}

Cases of culture-confirmed salmonellosis from 1995 to 2001 at the Michigan Department of Community Health (MDCH) Bureau of Epidemiology were analyzed. To determine the serotypes involved, the cases were merged with Salmonella records at the MDCH laboratory, which performs complete serotyping. Cases were matched by first and last name using EpiInfo 2004 v. 3.3 (CDC, Atlanta, GA). Cases remaining unmerged due to spelling errors of the first or last name were matched manually on a case-by-case basis. The final database includes each patient's address, age, sex, race, ethnicity, event date, and Salmonella serotypes.
To maintain the confidentiality of study subjects, a group level analysis without any identification of study subjects was performed. The institutional review boards for research involving human subjects at MDCH and Michigan State University approved the study protocol and the use of these data.

Age-standardized annual incidences (cases per 100,000 population) of infections with all Salmonella and the most common serotypes were calculated based on the appropriate population estimates of Michigan from1995 to 2001 (NCHS, 2000). The year 2000 standard population was used for age standardization (Anderson and Rosenberg, 1998). Poisson regression analysis was used to estimate the change in incidence (relative rate) between 1995 and 2001 and 1998 and 2001, along with the 95\% confidence interval (CI). (CDC, 2002a; Hardnett et al., 2004). The analysis was conducted using Proc Genmod in SAS v. 8.0 (SAS Institute, Cary, $\mathrm{NC}$ ).

To examine age differences, average annual incidence per 100,000 population (AAI) was calculated for the following age categories: $<1$, $1-4,5-9,10-29,30-39,40-59$, and $\geq 60$ years based on the variation in exposure and immunologic status. Because of the immunocompetent status and a relatively lower incidence of salmonellosis among people aged 40-59 years, this age group was used as a reference age category to compute rate ratios for other age groups. Age-standardized AAIs were calculated to study differences according to sex, race, ethnicity, and type of county of residence (Table 1). We grouped counties into urban or rural based on United States Census Bureau definitions: an urban county is any county containing a city of $>50,000$ people or an area that has at least 100,000 people and has a substantial commuting interchange with a city of greater than 50,000 people. Poisson regression analysis was used to determine the adjusted relative rates with their $95 \% \mathrm{CI}$.

\section{RESULTS}

From 1995 to 2001, 6797 culture-confirmed cases of salmonellosis were reported to MDCH, with an average annual incidence of 9.9/ 
Table 1. Average Annual Incidence of Human Infection with All Salmonella spp. by Age, Sex, Race, Ethnicity, Type of County of Residence, and Salmonella Serotype in Michigan, 1995-2001 (N =6797)

\begin{tabular}{|c|c|c|c|}
\hline & $\mathrm{N}$ & $A A I$ & $R R(95 \% C I)$ \\
\hline \multicolumn{4}{|l|}{ Age, years } \\
\hline$<1$ & 690 & 75.0 & 10.47 (9.54-11.48) \\
\hline $1-4$ & 842 & 22.1 & $3.08(2.82-3.36)$ \\
\hline $5-9$ & 534 & 10.3 & $1.44(1.30-1.59)$ \\
\hline $10-29$ & 1568 & 8.1 & $1.13(1.05-1.22)$ \\
\hline $30-39$ & 853 & 7.9 & $1.11(1.10-1.21)$ \\
\hline $40-59^{a}$ & 1277 & 7.2 & 1.00 \\
\hline$\geq 60$ & 974 & 8.8 & $1.23(1.13-1.33)$ \\
\hline \multicolumn{4}{|l|}{ Sex } \\
\hline Male ${ }^{a}$ & 3178 & 9.3 & 1.00 \\
\hline Female & 3567 & 10.1 & $1.08(0.82-1.33)$ \\
\hline \multicolumn{4}{|l|}{ Race $^{\mathrm{b}}$} \\
\hline White $^{\mathrm{a}}$ & 3207 & 5.6 & 1.00 \\
\hline Black & 737 & 6.8 & $1.30(1.20-1.41)$ \\
\hline Native American & 13 & 2.5 & $0.48(0.28-0.82)$ \\
\hline Asian/Pacific Islander & 25 & 1.6 & $0.37(0.25-0.54)$ \\
\hline Other & 54 & - & - \\
\hline Not stated & 28761 & - & - \\
\hline \multicolumn{4}{|l|}{ Ethnicity $^{\mathrm{b}}$} \\
\hline Hispanic & 71 & 2.9 & $1.30(1.03-1.65)$ \\
\hline Non-Hispanic ${ }^{a}$ & 1779 & 2.7 & 1.00 \\
\hline Not stated & 4947 & - & - \\
\hline \multicolumn{4}{|l|}{ Type of county } \\
\hline Urban & 5436 & 9.8 & 1.05 (0.99-1.11) \\
\hline Rural $^{\mathrm{a}}$ & 1359 & 9.5 & 1.00 \\
\hline \multicolumn{4}{|l|}{ Serotype } \\
\hline S. Typhimurium & 1598 & 2.3 & $0.59(0.56-0.63)$ \\
\hline S. Enteritidis & 1309 & 1.9 & $0.48(0.45-0.52)$ \\
\hline S. Heidelberg & 466 & 0.7 & $0.17(0.16-0.09)$ \\
\hline S. Newport & 222 & 0.3 & $0.08(0.07-0.09)$ \\
\hline Other serotypes ${ }^{a}$ & 2699 & 3.9 & 1.00 \\
\hline
\end{tabular}

a Reference category in Poisson regression analysis.

bSignificantly higher AAI for blacks and Hispanics should be interpreted with cuation because only 59\% and $27 \%$ of the cases had information on race and ethnicity, respectively.

$\mathrm{AAI}$, average annual incidence; RR, adjusted relative rate determined by Poisson regression analysis; $\mathrm{CI}$, confidence interval.

100,000 . Of this total, 6292 cases $(93 \%)$ have information on Salmonella serotype. The most common serotypes were $S$. Typhimurium (1596 cases, $26 \%)$, S. Enteritidis $(1309,22 \%)$, S. Heidelberg $(466,8 \%)$, and $S$. Newport $(222,4 \%)$. These serotypes accounted for $57 \%$ (3593 cases) of the total number of cases with a known serotype. The other 11 serotypes in the list of the 15 most common serotypes were: $S$. Java (178 cases, 3\%), S. Thompson (178 cases, 3\%), S. Oranienburg (174 cases, 3\%), S. Agona (157 cases, 3\%), S. Muenchen (130 cases, 2\%), S. Braenderup (119 cases, 2\%), S. Saintpaul (104 cases, $2 \%), S$. Infantis (101 cases, 2\%), S. Montevideo (99 cases, $2 \%$ ), S. Stanley (96 cases, $2 \%$ ), and $S$. Javiana (81 cases, $1 \%$ ).

\section{Temporal trends}

After an increasing trend from 1995 to 1998, the incidence of infection with all Salmonella serotypes significantly decreased by $25 \%$ (95\% CI, 31-18\% decrease) from 1998 to 2001: S. Typhimurium decreased by 39\% (95\% CI, 49-26\% decrease), and $S$. Enteritidis decreased by $32 \%$ (95\% CI, 44-18\% decrease) (Fig. 1). The incidence of $S$. Newport significantly increased by 101\% (95\% CI, 25-225\% increase) from 1998 to 2001 where as S. Heidelberg remained stable.

\section{Seasonality}

Overall, high percentages of Salmonella cases occurred between May and September, with 


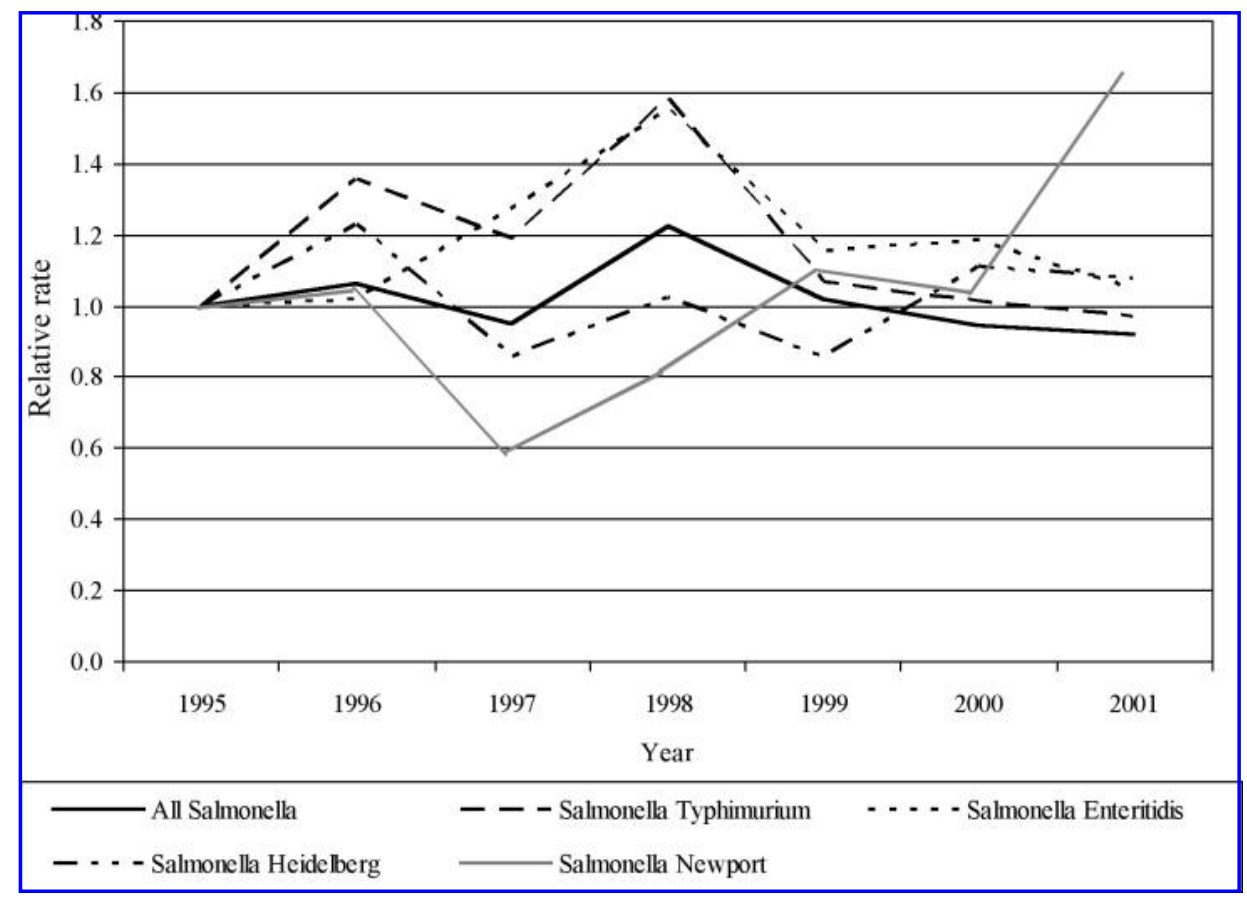

FIG. 1. Relative rates compared with 1995 of infection with all Salmonella and the most common serotypes in Michigan, 1995-2001.

the peak in July (Fig. 2). This general pattern was consistent for $S$. Typhimurium, S. Enteritidis, $S$. Heidelberg, and $S$. Newport.

\section{Type of county of residence}

The age-standardized AAI for infection with all Salmonella did not differ significantly in urban and rural counties. No significant difference in the age-standardized AAI was noted for $S$. Typhimurium (2.3 vs. 2.1; RR, 1.09; 95\% CI, 0.79-1.52), S. Enteritidis (1.9 vs. 1.9; RR, 1.00; 95\% CI, 0.70-1.42), S. Heidelberg (0.7 vs. 0.5; RR, $1.31 ; 95 \%$ CI, 0.69-2.51), or $S$. Newport (0.7 vs. 0.5 ; RR, $0.71 ; 95 \%$ CI, 0.27-1.83).

Age

The average incidence of infection with all Salmonella was highest among infants aged $<1$ year (AAI $=75.0)$ compared to other age categories. Incidence decreased abruptly after infancy, remained relatively constant through the adult years, and increased slightly among persons $>60$ years. The AAI for infants was significantly higher among infants aged 1-5 months than infants aged $6-11$ months (95.4 vs. 53.0; RR, 1.80; 95\% CI, 1.54-2.10). Similar pat- terns of age-specific incidence were noted for infections with $S$. Typhimurium, $S$. Enteritidis, $S$. Heidelberg, and $S$. Newport.

Sex

Age-standardized AAI was not different significantly between females and males for all Salmonella, S. Typhimurium (2.3 vs. 2.2; RR, 1.07; 95\% CI, 0.82-1.38), S. Enteritidis (1.9 vs. 1.8; RR, 1.07; 95\% CI, 0.80-1.42), S. Heidelberg (0.7 vs. 0.6 ; RR, $1.22 ; 95 \%$ CI, 0.75-1.99), and $S$. Newport (0.4 vs. 0.3 ; RR, 1.23 ; 95\% CI, 0.61-2.48).

Race

Of the 6797 Salmonella cases, only 4036 (59\%) have information on race. Among the cases in which race was known, blacks had a significantly higher age-standardized AAI than whites for infection with all Salmonella, $S$. Typhimurium (2.5 vs. 1.3; RR, 2.27; 95\% CI, 1.98-2.61), S. Enteritidis (1.4 vs. 1.1; RR, 1.35; 95\% CI, 1.13-1.62), S. Heidelberg (0.8 vs. 0.3; RR, 3.56; 95\% CI, 2.77-4.58) and S. Newport (0.3 vs. 0.1; RR, 2.83; 95\% CI, 1.92-4.18). Native Americans and Asians/Pacific Islanders had a significantly lower age-standardized AAI than whites. 


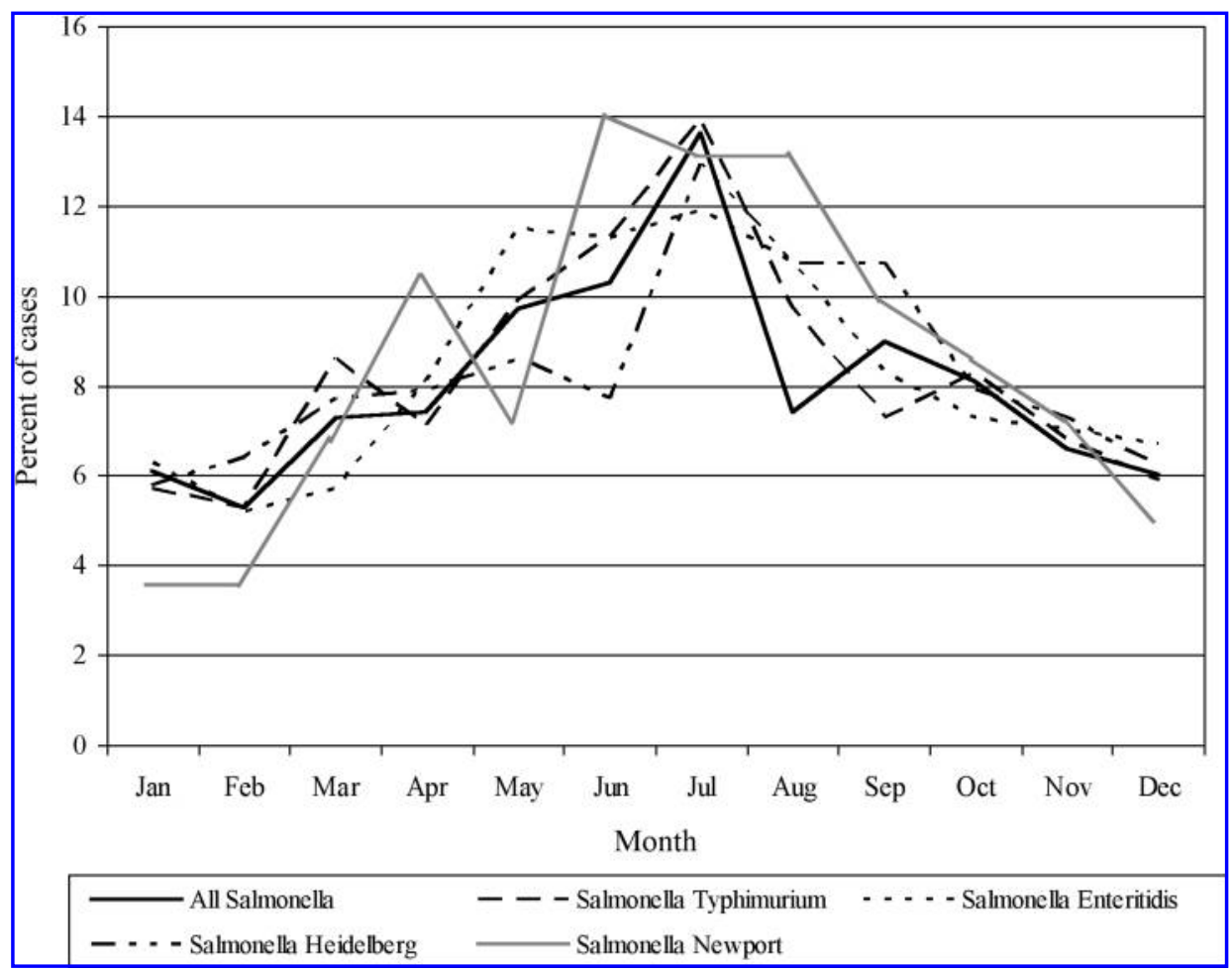

FIG. 2. Cases of infections with all Salmonella, S. Typhimurium, S. Enteritidis, S. Heidelberg, and S. Newport by month, in Michigan, 1995-2001.

\section{Ethnicity}

Only 1850 cases (27\%) have information on ethnicity. Among the cases whose ethnicity was known, Hispanics had a significantly higher age-standardized AAI than non-Hispanics for infection with all Salmonella and $S$. Enteritidis (1.0 vs. 0.5; RR, 1.9; 95\% CI, 1.212.98).

\section{Invasive salmonellosis}

Of the 6797 cases, 341 (5\%) Salmonella isolates were from blood and $6(<1 \%)$ were from cerebrospinal fluid, and the AAI of invasive salmonellosis was 0.5. The AAI of invasive salmonellosis was highest among infants aged $<1$ year (3.6) (Table 2). Seventy-four percent of the 347 invasive salmonellosis cases were caused by 10 Salmonella serotypes: S. Heidelberg $(19.3 \%)$, S. Typhimurium (18.7\%), S. Enteritidis (16.7\%), S. Typhi (3.7\%), S. Oranienburg (3.2\%), S. Dublin $(2.9 \%)$, S. Poona $(2.9 \%)$, S. Montevideo $(2.6 \%)$, S. Agona $(2.0 \%)$, and $S$. Hadar $(1.7 \%)$.

\section{DISCUSSION}

In this study, 6797 cases of human infections with Salmonella spp. were reported to the MDCH from 1995 to 2001 with an average of 971 cases annually and AAI of 9.9. This study revealed that the most common Salmonella serotypes in Michigan during those years were $S$. Typhimurium, $S$. Enteritidis, $S$. Heidelberg, and $S$. Newport. $S$. Typhimurium is ubiquitous in many food animals; $S$. Enteritidis and $S$. Heidelberg have poultry as the primary reservoir; and the primary reservoir for $S$. Newport is cattle (CDC, 2002b; Ferris et al., 2000; van Duijkeren et al., 2002; Wray and Wray, 2000).

The incidence of infections with all Salmonella, S. Typhimurium, and S. Enteritidis decreased significantly from 1998 to 2001. The decline in the incidence may suggest that important progress toward the reduction of salmonellosis to the national health objective of an AAI of 6.8 (CDC, 2002a; DHHS, 2003) is being made. The decline in incidence rates are unlikely to be due to changes in surveillance, be- 
Table 2. Cases of the Most Common Salmonella Serotypes Associated With Invasive Infection, By Age, in Michigan, 1995-2001

\begin{tabular}{|c|c|c|c|c|c|c|c|}
\hline & \multicolumn{6}{|c|}{ Age (years) } & \multirow[b]{2}{*}{$\begin{array}{l}\text { Total }(\%) \\
(\mathrm{n}=347)\end{array}$} \\
\hline & $\begin{array}{c}<1 \\
(\mathrm{n}=33)\end{array}$ & $\begin{array}{c}1-9 \\
(\mathrm{n}=71)\end{array}$ & $\begin{array}{c}10-19 \\
(\mathrm{n}=42)\end{array}$ & $\begin{array}{c}20-39 \\
(\mathrm{n}=74)\end{array}$ & $\begin{array}{c}40-59 \\
(\mathrm{n}=75)\end{array}$ & $\begin{array}{c}\geq 60 \\
(\mathrm{n}=50)\end{array}$ & \\
\hline S. Heidelberg & 7 & 12 & 11 & 15 & 17 & 5 & $67(19 \%)$ \\
\hline S. Typhimurium & 5 & 19 & 3 & 16 & 11 & 10 & $64(18 \%)$ \\
\hline$S$. Enteritidis & 3 & 14 & 6 & 9 & 17 & 9 & $58(17 \%)$ \\
\hline S. Typhi & 2 & 4 & 0 & 0 & 5 & 2 & $13(4 \%)$ \\
\hline S. Oranienburg & 1 & 2 & 2 & 4 & 1 & 1 & $11(3 \%)$ \\
\hline S. Dublin & 0 & 1 & 2 & 5 & 1 & 1 & $10(3 \%)$ \\
\hline S. Poona & 0 & 4 & 0 & 2 & 4 & 0 & $10(3 \%)$ \\
\hline S. Montevideo & 4 & 1 & 1 & 1 & 2 & 0 & $9(2 \%)$ \\
\hline Other Salmonella spp. & 11 & 14 & 17 & 22 & $1 \overline{7}$ & 22 & $103(29 \%)$ \\
\hline AAI for all Salmonella & 3.6 & 0.8 & 0.4 & 0.4 & 0.4 & 0.5 & 0.5 \\
\hline
\end{tabular}

AAI, average annual incidence; $\mathrm{RR}$, adjusted relative rate determined by Poisson regression analysis; $\mathrm{CI}$, confidence interval.

cause no modifications to the diagnostic criteria for salmonellosis were made and only passive surveillance was conducted throughout the study period.

The decline in the incidence of all Salmonella, $S$. Typhimurium, and $S$. Enteritidis in this study is consistent with the trend of salmonellosis in the United States from 1998 to 2001. Based on the Summary of Notifiable Diseases, the incidence of salmonellosis in the United States decreased from 16.2 in 1998 to 14.2 in 2001 (CDC, 2002a). Based on the Public Health Laboratory Information System (PHLIS), the number of $S$. Typhimurium isolates decreased from $8818(3.3 / 100,000)$ in 1998 to 6999 $(2.5 / 100,000)$ in 2001. S. Enteritidis decreased from $6029(2.2 / 100,000)$ in 1998 to 5614 $(2.0 / 100,000)$ in 2001 (CDC, 2002b). However, a recent FoodNet report comparing 2005 to the average annual incidence for 1996-1998, found only the incidence of $S$. Typhimurium decreased significantly in $2005(42 \% ; 95 \% \mathrm{CI}$, $34-48 \%)(C D C, 2006)$. The estimated incidence of S. Enteritidis increased $25 \%(95 \% \mathrm{CI}, 1-55 \%)$, and $S$. Heidelberg increased 25\% (95\% CI, $1-54 \%$ ). The estimated incidence of $S$. Newport increased compared with the baseline, but the increase was not statistically significant (CDC, 2006).

The reasons for the decrease in the incidence rates in Michigan are not clear. However, several reports have suggested that the nationwide decrease in the incidence of many Salmonella serotypes, including $S$. Typhimurium and $S$. Enteritidis, may be partly attributed to several control measures including the implementation of the Pathogen Reduction/Hazard Analysis Critical Control Point (HACCP) systems regulations in meat and poultry slaughter and processing plants by the United States Department of Agriculture (USDA) Food Safety Inspection Service (FSIS) on July 25, 1996 (CDC, 2002a; FSIS, 1996). Additional interventions that may have resulted in decreases in the incidence rates include egg-quality assurance programs for $S$. Enteritidis and public health food safety education such as FIGHT BAC! that targets consumers and food handlers (CDC, 2002a; FIGHT BAC).

Even though the incidence of all Salmonella infections decreased significantly from 1998 to 2001, the incidence of $S$. Newport increased significantly during this period. This increase is consistent with the trend of $S$. Newport infection in the United States. The number of $S$. Newport isolates reported to the CDC increased by $23 \%$ from 2566 in 1995 to 3158 in 2001 (CDC, 2002b). In the FoodNet sites, the incidence of $S$. Newport increased by $32 \%$ from 1996 to 2001 (CDC, 2002a). The reasons for the significant increase in the incidence of $S$. Newport from 1998 to 2001 in Michigan are not known. In the United States, increases in the incidence of $S$. Newport were due to the emergence of multidrug-resistant $S$. Newport (CDC, 2002b; Gupta et al., 2003). The increase in the 
incidence of infection with $S$. Newport in Michigan should be further investigated for the possible risk factors and for the presence of multidrug-resistant strains. This is important because human infections with multidrugresistant strains of Salmonella, such as $S$. Typhimurium DT104, have worse outcomes than infections with antimicrobial-susceptible strains (Helms et al., 2002; Martin et al., 2004; Varma et al., 2005).

Although the incidence of $S$. Heidelberg remained stable, the public health importance of this serotype cannot be underestimated. Approximately $1900 \mathrm{~S}$. Heidelberg isolates were reported to the PHLIS each year from 1995 through 2004 (CDC, 2005). Furthermore, S. Heidelberg is the third most commonly reported serotype to cause human illness in 1998 and the fourth most commonly reported to cause human illness in 1999 to 2001, 2003 and 2005 (CDC, 2005). Eggs and chicken have been implicated in $S$. Heidelberg infections (Hennessy et al., 2004; MacDoughall et al., 2004). A recent report revealed that the most common food vehicles implicated in $S$. Heidelberg outbreaks in the United States were poultry, eggs, egg-containing food items, pork, and beef (Chittick et al., 2006).

Similar to findings in other studies (Olsen et al., 2001; Schutze et al., 1995. Trevejo et al., 2003), infections with Salmonella occurred more frequently in the summer months. This may be due to more people cooking foods of animal origin at picnics, barbecues, and on camping trips. During these activities safety controls such as thermostat-controlled cooking, refrigeration, and washing facilities are usually not available (Olsen et al., 2001). Furthermore, humid and hot conditions in summer favor the rapid growth of Salmonella in foods that are not kept refrigerated.

This study shows that the age-standardized AAI of $S$. Typhimurium, $S$. Enteritidis, $S$. Heidelberg, and $S$. Newport did not differ significantly between residents in urban and rural counties. These findings suggest similar levels of exposure to potential sources of these serotypes, possibly as a result of a more integrated food distribution system and the increased consumption of meat and poultry (Altekruse and Swerdlow, 1996).
The incidence of infections with Salmonella in this study were highest among infants aged $<1$ year, similar to other studies (Olsen et al., 2001; Schutze et al., 1995; Trevejo et al., 2003; Voetsch et al., 2004). Beside the immature immune system (Buzby, 2001), other reasons for the high incidence among infants in Michigan are largely unknown. Olsen et al. suggested that the reasons for the high incidence among infants aged $<1$ year may include host susceptibility and exposure differences (Olsen et al., 2001). Infants may contract salmonellosis from infected family members (Delarocque-Astagneau et al., 2000; Wilson et al., 1982), contaminated infant formula (Park et al., 2004), or food containing undercooked eggs, meat, or vegetables (Delarocque-Astagneau et al., 2000; Espie et al., 2005). A significantly higher incidence of salmonellosis among infants aged 1-5 months compared to infants aged 6-11 months suggest that modes of transmission involving non-food vehicles may play an important role. The infant behavior of putting things in the mouth (Berger and Thompson, 1995) may also contribute to the high incidence of infant salmonellosis.

The finding that the incidence was higher among blacks compared to whites in this study should be interpreted with caution because only $59 \%$ of the cases have information on race. However, the results indicate the magnitude of salmonellosis problem among blacks in Michigan and further studies should be conducted to determine the actual risk factors. Among cases whose race was known, the incidence of infection with $S$. Typhimurium, S. Enteritidis, $S$, Heidelberg, and $S$. Newport were significantly higher among blacks compared to whites. An analysis of FoodNet data for the years 1998-2001 also demonstrated a higher incidence of $S$. Enteritidis among blacks (Marcus et al., 2002).

Only $27 \%$ of the cases in this study have information on ethnicity. Among cases whose ethnicity was known, the incidence of infection with $S$. Enteritidis was significantly higher among Hispanics than non-Hispanics. An analysis of FoodNet data for 2000-2001 demonstrated that Hispanics were more likely than non-Hispanics to eat sprouts, parsley, cilantro, mangoes, yogurt, soft ice cream, unpasteurized milk, runny eggs, and oysters (Banerjee et al., 
2002). We speculate that the high incidence of $S$. Enteritidis among Hispanics in Michigan may be due to frequent consumption of undercooked eggs or foods containing undercooked eggs such as mayonnaise, hollandaise sauce, ice creams, and desserts. In the period 1994-1996, Hispanics consumed more eggs than whites (USDA-ARS). Since only $27 \%$ of the cases in this study have information on ethnicity, the significantly higher incidence of $S$. Enteritidis in Hispanics in this study should be interpreted with caution.

This study shows that the incidence of invasive salmonellosis in Michigan was highest among infants aged $<1$ year. This finding is a public health concern because invasive salmonellosis can result in meningitis, osteomyelitis, endocarditis, arthritis, urinary-tract infection, and pneumonia (Pegues et al., 2005). The reasons for the high incidence of invasive salmonellosis among infants in Michigan are not known. However, other studies suggest that immunocompromise and predisposing clinical conditions (eg, hematological malignancy or sickle-cell hemoglobinopathy) are possible risk factors (Yang et al., 2002).

The main limitation of this study is that it was based on passive surveillance data. Although most culture-confirmed cases are reported to the $\mathrm{MDCH}$, this surveillance system unavoidably underestimates the actual incidence (Voetsch et al., 2004). To be identified as a laboratory-confirmed Salmonella case, a person must have symptoms that are severe enough to consult a physician, and provide a clinical specimen. To be counted as a case, the physician or laboratory must report the case to the local health department. The degree of underreporting of salmonellosis has been estimated to be between 19- and 38-fold (Mead et al., 1999; Voetsch et al., 2004). Missing information on race and ethnicity is another limitation in this study. The surveillance data set contained both sporadic and outbreak cases. Therefore, large outbreaks may have led to certain demographic characteristics to be more represented.

Despites the limitations of the data and the decreasing trend in the incidence of all Salmonella, this study reveals the emergence of $S$. Newport infection and higher incidence of sal- monellosis among infants, blacks, and Hispanics in Michigan. Information from this study can be used by the state and local health departments of Michigan to enhance salmonellosis prevention efforts by rationalizing the allocation of appropriate public health resources and personnel. Further studies should be conducted to determine the risk factors for the emergence of $S$. Newport and the high incidence of Salmonella serotypes among at-risk populations.

\section{ACKNOWLEDGMENTS}

We would like to thank Sally A. Bidol, Foodborne Epidemiologist, $\mathrm{MDCH}$, for her help in providing the data. We also thank Weixing Song, Research Assistant, Department of Statistics, Michigan State University, for assistance in Poisson regression analysis.

This research was supported in part by funding from the office of the Research Associate Dean of the College of Veterinary Medicine at Michigan State University as a supplement to the NIH Contract No. N01-AI-30058 (Microbiology Research Unit, MSU).

\section{REFERENCES}

Anderson RN, Rosenberg HM. Age standardization of death rates: implementation of the year 2000 standard. Natl Vital Stat Rep 1998;47:1-16, 20.

Altekruse SF, Swerdlow DL. The changing epidemiology of foodborne diseases. Am J Med Sci 1996;311:23-29.

Banerjee A, Frierman M, Hurd S, Jones T, McCarthy P, Medus C, Shiferaw B, Vugia D, Zansky S, and the EIP FoodNet Working Group. Characterization of high-risk food consumption practices among the Hispanic population, FoodNet 2000-2001. Chicago: Infectious Diseases Society of America, 2002. Available at www.cdc.gov/foodborne/publications/29_banerjee_2002.pdf. Accessed 24 December 2006.

Buzby JC. Children and microbial foodborne illness. Food Rev 2001;24:32-37.

Berger KS, Thompson RA. The Developing Person: Through Childhood and Adolescence. New York: Worth, 1995.

CDC (Centers for Disease Control and Prevention). Summary of notifiable diseases, United States, 1995-2001. Available at: www.cdc.gov/ncidod/dbmd/phlisdata/ salmonella.htm. 
CDC. Public Health Laboratory Information System (PHLIS). Salmonella annual summaries, 2002. Available at www.cdc.gov/ncidod/dbmd/phlisdata/salmonella.htm.

CDC. Preliminary FoodNet Data on the Incidence of Foodborne Illnesses, Selected Sites, United States, 2001. MMWR 2002a;51;325-9. Available at www.cdc.gov/ mmwr/preview/mmwrhtml/mm5115a3.htm. Accessed 24 December 2006.

CDC. Salmonella Surveillance: Annual Summary, 2004. U.S. Department of Health and Human Services, Atlanta, GA, 2005.

CDC. Preliminary FoodNet Data on the incidence of infection with pathogens transmitted commonly through food-10 States, United States, 2005. MMWR 2006; 55:392-395. Available at jama.ama-assn.org/cgi/reprint/ 295/19/2241.pdf. Accessed 24 December 2006.

Chittick P, Sulka A, Tauxe RV, Fry AM. A summary of national reports of foodborne outbreaks of Salmonella Heidelberg infections in the United States: clues for disease prevention. I Food Prot 2006;69:1150-1153.

Delarocque-Astagneau E, Bouillant C, VaillantV, Bouvet P, Grimont PA, Desenclos JC. Risk factors for the occurrence of sporadic Salmonella enterica serotype Typhimurium infections in children in France: a national case-control study. Clin Infect Dis 2000;31:488-492.

DHHS (Department of Health and Human Services). 2003. Healthy People 2010: Understanding and Improving Health (2nd ed.). Washington, DC: U.S. Government Printing Office, 2003. Available at www.healthy people.gov/Document/tableofcontents.htm\#volume1. Accessed 24 December 2006.

Espie E, Weill FX, Brouard C, Capek I, Delmas G, Forgues AM, Grimont F, de Valk H. Nationwide outbreak of Salmonella enterica serotype Agona infections in infants in France, linked to infant milk formula, investigations ongoing. Euro Surveill 2005;10;54. Available at fulltext.bdsp.tm.fr/ Invs / EuroSurveillance/Vol10/1/vol10n1.pdf?04179K4X19-7G933-47M0G-9GX63. Accessed 24 December 2006.

Ferris KE, Flugard BR, Timm JM. 2000. Salmonella serovars from animals and related sources reported during July 1999-June 2000. Proceedings of the 104th Annual Meeting of the United States Animal Health Association, Birmingham, Alabama, October 20-27, 2000. Richmond, VA: Pat Campbell \& Associates and Carter Printing Company, pp. 521-526.

FIGHT BAC. Partnership for Food Safety Education. Fight BAC!: Safe Food Handling. Available at www.fightbac.org/ content/view/6/11/. Accessed 7 February 2006.

Frenzen P, Riggs T, Buzby J, Breuer T, Roberts T, Voetsch D, Reddy S, and the FoodNet Working Group. Salmonella cost estimate updated using FoodNet data. Food Rev 1999;22:10-15.

FSIS (USDA Food Safety and Inspection Service). 1996. New rules for improving the safety of meat and poul- try: Pathogen Reduction/Hazard Analysis Critical Control Points. Available at www.fsis.usda.gov/Science/ Hazard_Analysis_\&_Pathogen_Reduction/index.asp. Accessed March 20, 2006.

Gomez TM, Motarjemi Y, Miyagawa S, Kaferstein FK, Stohr K. Foodborne salmonellosis. World Health Stat Q 1997;50;81-89.

Gupta A, Fontana J, Crowe C, Bolstorff B, Stout A, Van Duyne S, Hoekstra MP, Whichard JM, Barrett TJ, Angulo FJ, and the National Antimicrobial Resistance Monitoring System PulseNet Working Group. Emergence of multidrug-resistant Salmonella enterica serotype Newport infections resistant to expanded-spectrum cephalosporins in the United States. J Infect Dis 2003;188:1707-1716.

Hardnett FP, Hoekstra RM, Kennedy M, Charles L, Angulo FJ. Epidemiologic issues in study design and data analysis related to FoodNet activities. Clin Infect Dis 2004;38:S121-S126.

Helms M, Vastrup P, Gerner-Smidt P, Molbak K. Excess mortality associated with antimicrobial drug-resistant Salmonella Typhimurium. Emerg Infect Dis 2002;8: 490-495.

Hennessy TW, Cheng LH, Kassenborg H, Ahuja SD, Mohle-Boetani J, Marcus R, Shiferaw B, Angulo FJ, and Emerging Infections Program FoodNet Working Group. Egg consumption is the principal risk factor for sporadic Salmonella serotype Heidelberg infection: a case-control study in FoodNet sites. Clin Infect Dis 2004;38:S237-S243.

MacDougall L, Fyfe M, McIntyre L, Paccagnella A, Cordner K, Kerr A, Aramini J. Frozen chicken nuggets and strips-a new identified risk factor for Salmonella Heidelberg infection in British Columbia, Canada. J Food Prot 2004;67:1111-1115.

Marcus R, Rabatsky-Ehr T, Lay J, Mohle-Boetani J, Farley M, Medus C, Shiferaw B, Hawkins M, Zansky S, Jones T, Hadler J. Age, Ethnic and Racial Disparity in Salmonella serotype Enteritidis (SE): FoodNet, 1998-2000. International Conference on Emerging Infectious Diseases. Atlanta, GA, March 2002. Available at www.cdc.gov/foodborne/publications/180-marcus_2002.pdf. Accessed 24 December 2006.

Martin LJ, Fyfe M, Dore K, Buxton JA, Pollari F, Henry B, Middleton D, Ahmed R, Jamieson F, Ciebin B, McEwen SA, Wilson JB, and Multi-Provincial Salmonella Typhimurium Case-Control Study Steering Committee. Increased burden of illness associated with antimicrobialresistant Salmonella enterica serotype Typhimurium infections. I Infect Dis 2004;189:377-384.

Mead PS, Slutsker L, Dietz V, McCaig LF, Bresee JS, Shapiro C, Griffin PM, Tauxe RV. Food-related illness and death in the United States. Emerg Infect Dis 1999;5: 607-625.

MDCH (Michigan Department of Community Health). Appendix A: Rural and urban county listing. In: 2004 Epidemiologic profiles of HIV / AIDS in Michigan. Avail- 
able at www.michigan.gov/documents/2004_Profiles_ 104189_7.pdf. Accessed 24 December 2006.

NCHS (National Center for Health Statistics). BridgedRace Population Estimates, United States, 1990-2002, By Age Groups. Compiled from the April 1, 2000 resident population developed by the Bureau of the Census in collaboration with the NCHS on CDC WONDER On-line Database. Available at wonder.cdc.gov/population.html. Accessed September 10, 2005.

Olsen SJ, MacKinnon LC, Goulding JS, Bean NH, Slutsker L. Surveillance for foodborne-disease outbreaks-United States, 1993-1997. MMWR 2000;49: 1-62; erratum SS-1. Available at www.cdc.gov/mmwr/ preview/mmwrhtml/ss4901a1.htm. Accessed 24 December 2006.

Olsen SJ, Bishop R, Brenner FW, Roels TH, Bean N, Tauxe $\mathrm{RV}$, Slutsker L. The changing epidemiology of Salmonella: trends in serotypes isolated from humans in the United States, 1987-1997. J Infect Dis 2001;183:753-761.

Pang T, Bhutta ZA, Finlay BB, Altwegg M. Typhoid fever and other salmonellosis: a continuing challenge. Trends Microbiol 1995;3:253-255.

Park JK, Seok WS, Choi, BJ, Kim HM, Lim BK, Yoon SS, Kim S, Kim YS, Park YJ. Salmonella enterica serovar London infections associated with consumption of infant formula. Yonsie Medical J 2004;45:43-48.

Pegues DA, Ohl ME, Miller SI. 2005. Salmonella species, including Salmonella Typhi. In Mandel GL, Bennet JE, Dolin R (eds.): Principles and Practice of Infectious Diseases, 6th edition. New York: Churchill, Livingstone, 2005:2636-2654.

Sanchez S, Hofacre CL, Lee MD, Maurer JJ, Doyle MP. Animal sources of salmonellosis in humans. I Am Vet Med Assoc 2002;221:492-497.

Schutze GE, Flick EL, Pope SK, Lofgren JP, Kirby RS. Epidemiology of salmonellosis in Arkansas. South Med J 1995;88:195-199.

Sivapalasingam S, Friedman CR, Cohen L, Tauxe RV. Fresh produce: a growing cause of outbreaks of foodborne illness in the United States, 1973 through 1997. J Food Prot 2004;67:2342-2353.

Trevejo RT, Courtney JG, Vugia DJ. Epidemiology of salmonellosis in California, 1990-1999: morbidity, mor- tality, and hospitalization costs. Am J Epidemiol 2003;157;48-57.

Food Surveys Research Group, USDA-ARS (United States Department of Agriculture-Agriculture Research Service), Beltsville, MD. Available at www.ars.usda.gov/SP2User Files/Place/12355000/pdf/Origin94.PDF.

van Duijkeren E, Wannet WJ,Houwers DJ, van Pelt W. Serotype and phage type distribution of Salmonella strains isolated from humans, cattle, pigs, and chickens in the Netherlands from 1984 to 2001. J Clin Microbiol 2002;40: 3980-3985.

Varma JK, Molbak K, Barrett TJ, Beebe JL, Jones FF, Rabatsky-Her T, Smith KE, Vugia DJ, Chang HG, Angulo FJ. Antimicrobial-resistant nontyphoidal Salmonella is associated with excess bloodstream infections and hospitalizations. I Infect Dis 2005;191:554-561.

Voetsch AC, Van Gilder TJ, Angulo FJ, Farley MM, Shallow S, Marcus R, Cieslak PR, Deneen VC, Tauxe RV, and Emerging Infections Program FoodNet Working Group. FoodNet estimate of the burden of illness caused by nontyphoidal Salmonella infections in the United States. Clin Infect Dis 2004;38:S127-S134. Wilson R, Feldman RA, Davis J, LaVenture M. Salmonella in infants: the importance of intrafamilial transmission. Pediatrics 1982;69: 436-438.

WHO Global Salm-Surv Progress Report II (2000-2005). WHO Press, World Health Organization, Geneva, Switzerland.

Wray C, Wray A. Salmonella in Domestic Animals. New York: CABI, 2000.

Yang YJ, Huang MC, Wang SM, Wu JJ, Cheng CP, Liu CC. Analysis of risk factors for bacteremia in children with nontyphoidal Salmonella gastroenteritis. Eur J Clin Microbiol Infect Dis 2002;21:290-293.

Address reprint requests to: A. Mahdi Saeed, PhD Michigan State University 165 National Food Safety and Toxicology Building East Lansing, MI 48824

E-mail: saeeda@msu.edu 
This article has been cited by:

1. J. Oloya , D. Doetkott , M.L. Khaitsa . 2009. Antimicrobial Drug Resistance and Molecular Characterization of Salmonella Isolated from Domestic Animals, Humans, and Meat ProductsAntimicrobial Drug Resistance and Molecular Characterization of Salmonella Isolated from Domestic Animals, Humans, and Meat Products. Foodborne Pathogens and Disease 6:3, 273-284. [Abstract] [PDF] [PDF Plus]

2. M. CHANG, S. L. GROSECLOSE, A. A. ZAIDI, C. R. BRADEN. 2008. An ecological analysis of sociodemographic factors associated with the incidence of salmonellosis, shigellosis, and E. coli O157:H7 infections in US counties. Epidemiology and Infection 1. [CrossRef]

3. J. Oloya , M. Theis , D. Doetkott , N. Dyer , P. Gibbs , M.L. Khaitsa . 2007. Evaluation of Salmonella Occurrence in Domestic Animals and Humans in North Dakota (2000-2005)Evaluation of Salmonella Occurrence in Domestic Animals and Humans in North Dakota (2000-2005). Foodborne Pathogens and Disease 4:4, 551-563. [Abstract] [PDF] [PDF Plus] 